\title{
The Effects of Labeling on Environmental Self-identity
}

\author{
Li Zheng ${ }^{1,2}$, Zepeng Tong ${ }^{1,2}$, Yan Sun ${ }^{1,2 *}$ \\ ${ }^{1}$ Key Laboratory of Behavioral Science, Institute of Psychology, Chinese Academy of Sciences, Beijing, 100101, China \\ ${ }^{2}$ Department of Psychology, University of Chinese Academy of Sciences, Beijing, 100049, China
}

\begin{abstract}
Labeling refers to the behavior that a person uses specific words to label and tends to describe according to the label. For example, when labeled as "environmentally-conscious", one will enhance his/her pro-environmental behaviors. Thus that will strengthen his/her environmental self-identity, which, in turn, will promote pro-environmental behaviors. This paper looks into the effects of four labels on proenvironmental behaviors. The study into elephant protection found that negative labels can significantly encourage elephant protection and discourage the consumption of elephant-related products. This research will provide a policy tool for environmental organizations and relevant governmental departments.
\end{abstract}

\section{Introduction}

Wild animals play an important role in stabilizing the ecosystem. They used to live in the wild for a long time. However, as human society evolves, they have become indispensable strategic resources in our daily life and production. Although elephants are an important member of the wildlife family, more than 20,000 of them are hunted and killed in Africa every year to meet people's demand for ivory.

When it comes to elephant protection, we need to understand what factors play a role in such a proenvironmental behavior. Some scholars believe that environmental self-identity is an important predictor.

Self-identity is defined as self-description through certain labels [1]. It is associated with certain behaviors [2]. Studies have shown that there is a link between selfidentity and its corresponding environmental intentions and behaviors, such as recycling [3], environmental behaviorism [4], and the purchase of genetically modified food [1]. In other words, certain self-identity (e.g. recycling identity) is positively related with certain behaviors (e.g. recycling). Recent studies even suggest that environmental self-identity can be separated from self-identity and help predict pro-environmental behaviors. For example, Whitmarsh and O'Neill (2010) [5] found that green identity is related to water and energy saving, waste reduction, and eco-friendly purchasing.

Environmental self-identity can be defined as the degree to which people regard themselves as environmentfriendly. Studies have demonstrated that enhanced environmental self-identity will increase proenvironmental behaviors, which means that environmental self-identity serves as an important predictor of pro-environmental behavior.

Labeling people to remind their environmental consciousness can promote pro-environmental behaviors and strengthen environmental self-identity. For example, the identity of being a green consumer can significantly increase green consumption. Sparks and Shepherd (1992) ${ }^{[6]}$ found that people who identify themselves as green consumers are more likely to buy organic food than those who do not. A large number of studies have revealed that identity may rule over attitude when our role identity determines our behaviors, no matter how we feel about the behavior ${ }^{[7]}$. Some studies suggest that identity is a good predictor of pro-environmental behaviors.

For instance, people who have a strong environmental identity are more likely to save energy, reduce waste, and pursue eco-shopping ${ }^{[5]}$. They are also more likely to engage in pro-environmental behaviors, recycling, purchase fair trade products, and avoid flying to holiday destinations ${ }^{[8]}$. They are economical in energy and paper use and are keen on green energy and sustainable products [9-10].

Labeling refers to the description of individuals through words or passages ${ }^{[11]}$. When one is labeled, due to self-verification, self-identity, self-image management, and cognitive or emotional reasons, one tends to behave as the label describes, as observed in the labeling theory ${ }^{[12]}$. Labeling, no matter whether it is positive or negative, weighs heavily on self-perception and guides individual behaviors ${ }^{[13]}$. In this research, the purpose is to look into the effects of different types of labels on proenvironmental behaviors. The hypothesis that enabling decision-makers' emotion labels (positive/negative), personality labels, and behavior labels can improve elephant protection will be tested.

\section{Research Methodology}

\subsection{Research participants}

The questionnaires were made on Wenjuanxing, an online

*Corresponding author's e-mail: suny@psych.ac.cn 
questionnaire-making platform, and distributed through WeChat, a messaging application, to 301 participants, $44 \%$ of whom were women and $57 \%$ of whom were aged 31 40.

\subsection{Questionnaire Design}

All subjects ( $\mathrm{N}=301)$ were randomly assigned to five experimental scenarios: positive emotion $(\mathrm{N}=61)$, negative emotion $(\mathrm{N}=59)$, personality label $(\mathrm{N}=61)$, behavior label $(\mathrm{N}=63)$ as well as the control group $(\mathrm{N}=57)$. The only difference between these five scenarios lied in background materials.

In this study, the subjects were divided into five groups with four experimental groups: negative emotion group, positive emotion group, personality group, behavior group, and one control group. In a between-subject design, the formal experiment required subjects in the experimental groups to read the corresponding background materials first, read the prominent environmentalism text label for 30 seconds (the font in bold), and then finish other questions.

1. Background

In the late 1970s, about 1.3 million elephants lived on the African continent, but today their numbers have plummeted to about 400,000 , a decline of nearly 70 percent within 40 years. More than 20,000 elephants are illegally hunted and killed in Africa each year due to the demand for ivory.

\section{Babel Design}

Negative emotion label: elephants, credited as "engineers" of nature, are indispensable members of the terrestrial ecosystem. Their daily activities affect their own habitats and also the living conditions of other species in the same area. You must be as saddened as we are to see elephant populations plummet over the past few decades due to illegal poaching.

Positive emotion label: elephants, credited as "engineers" of nature, are indispensable members of the terrestrial ecosystem. Their daily activities affect their own habitats and also the living conditions of other species in the same area. You must be as happy as we are to see elephant populations recover in the past two years due to reduced poaching.

Personality label: elephants, credited as "engineers" of nature, are indispensable members of the terrestrial ecosystem. Their daily activities affect their habitats and also the living conditions of other species in the same area. We are about to launch a global elephant protection campaign, and we invite you to join us. You will one of our elephant guardians.

Behavior label: elephants, credited as "engineers" of nature, are indispensable members of the terrestrial ecosystem. Their daily activities affect their habitat and also the living conditions of other species in the same area. We are about to launch a global elephant protection campaign, and we invite you to join us and say "No" to ivory products.

The questionnaire of willingness to buy ivory products included eight items:

- What do you think of the use of ivory products by others?

-What do you think of the purchase of ivory products by others?

-What do you think of the purchase of elephant-related products?

- To what extent do you agree that ivory products are a symbol of wealth, identity, and status?

- To what extent do you agree that "if the purchase of ivory products is legalized and unregulated, I will buy them in the next 12 months?"

- To what extent do you agree that "if I see ivory products on sales in the local market during overseas travel, I will buy them?"

- To what extent do you agree that "only strict laws and punishments can prevent people from buying ivory products?"

-What do you think of the purchase of ivory products?

All items were answered on a seven-point scale from "strongly disagree/very unwilling" to "strongly agree/very willing". Finally, the average scores were calculated. The larger the value, the stronger the desire to protect elephants. The Cronbach's alpha stood at 0.785 .

The questionnaire of the willingness to engage in the elephant protection activities included three items:

- Are you willing to participate in elephant protection activities held by relevant organizations?

- Are you willing to publicize relevant information and knowledge of elephant protection?

- Are you willing to report to relevant authorities if you find others peddling ivory products?

All items were answered on a seven-point scale from "very unwilling" to "very willing". Finally, the average scores were calculated. The larger the value, the stronger the desire to protect elephants. The Cronbach's alpha stood at 0.840 .

The questionnaire of willingness to donate for elephant protection included two items:

- Are you willing to donate money to non-profit organizations that engage in elephant protection?

- If you had 100 yuan, how much would you like to donate to a project for the protection of elephants and their habitats launched by a credible organization. The two items measured the willingness to donate and the specific amount.The questionnaire is also internally consistent, proved by Cronbach's alpha test.

\subsection{Research Design}

A between-subjects design was adopted in this study. During the formal experiment, participants first read the corresponding background materials and then completed the questionnaires. They included "willingness to buy ivory products", "willingness to engage in elephant protection activities", "willingness to donate for elephant protection", "willingness to follow elephant protection knowledge and information" and demographic information was required. 


\section{Results}

\subsection{Descriptive Statistics:}

The analysis of descriptive statistics shows that the willingness to consume ivory products is kept at a low level. Meanwhile, the willingness to protect elephants, donate money, and follow elephant protection information is high. The donation amount is reasonable. Consumption willingness is negatively related with protection willingness, donation willingness, donation amount, and willingness to follow elephant protection information.

$(1=$ consumption willingness; $2=$ protection willingness; $3=$ donation willingness; $4=$ donation amount; $5=$ willingness to follow elephant protection information)

Table1. The mean and standard deviation of elephant protection

\begin{tabular}{|c|c|c|c|c|c|c|c|}
\hline Variables & $\mathrm{M}$ & $\mathrm{SD}$ & Group1 & Group2 & Group3 & Group4 & Group5 \\
\hline 1 & 1.69 & 0.89 & 1.00 & & & & \\
\hline 2 & 5.62 & 1.32 & $-0.42^{* *}$ & 1.00 & & & \\
\hline 3 & 5.02 & 1.84 & $-0.56^{* *}$ & $0.66^{* *}$ & 1.00 & & \\
\hline 4 & 58.29 & 37.58 & $-0.46^{* *}$ & $0.48^{* *}$ & $0.65^{* *}$ & 1.00 & \\
\hline 5 & 5.49 & 1.61 & $-0.33^{* *}$ & $0.61^{* *}$ & $0.54^{* *}$ & $0.42^{* *}$ & 1.00 \\
\hline
\end{tabular}

Note: $\mathrm{N}=301 .{ }^{*} \mathrm{p}<0.05,{ }^{* *} \mathrm{p}<0.01$.

\subsection{ANOVA:}

One-way ANOVA was used to test the statistical significance among the four experimental groups and the control group. The results reveal a statistical significance between the two groups in terms of the willingness to consume ivory products, the willingness to engage in elephant protection, the willingness to donate money, and donation amount. However, no statistical significance is shown in the willingness to follow elephant protection information.

In addition, another test shows that the negative emotion group shows a lower willingness to consume ivory products than the positive emotion group $(\Delta M=-0.32$ $\mathrm{P}<0.05)$. The results of the ANOVA are shown in Table 2 below.

Table 2. Statistical Significance Test of Variables in Different Label Groups

\begin{tabular}{|c|c|c|c|c|c|}
\hline Variables & $\begin{array}{c}\text { Consumption } \\
\text { willingness }\end{array}$ & $\begin{array}{c}\text { Protection } \\
\text { willingness }\end{array}$ & $\begin{array}{c}\text { Donation } \\
\text { willingness }\end{array}$ & $\begin{array}{c}\text { Donation } \\
\text { amount }\end{array}$ & $\begin{array}{c}\text { Willingness to follow } \\
\text { information }\end{array}$ \\
\hline $\begin{array}{c}\text { Negative emotion } \\
\text { group }\end{array}$ & 1.40 & 5.69 & 5.20 & 66.29 & 5.44 \\
\hline $\begin{array}{c}\text { Positive emotion } \\
\text { group }\end{array}$ & 1.71 & 5.87 & 5.46 & 67.07 & 5.54 \\
\hline $\begin{array}{c}\text { Personality label } \\
\text { group }\end{array}$ & 1.63 & 5.62 & 5.03 & 61.97 & 5.49 \\
\hline $\begin{array}{c}\text { Behavior label } \\
\text { group }\end{array}$ & 1.62 & 5.82 & 5.24 & 54.59 & 5.81 \\
\hline Control group & 2.09 & 5.05 & 4.11 & 40.77 & 5.14 \\
\hline $\mathrm{F}$ & 4.87 & 3.74 & 4.96 & 5.16 & 1.32 \\
\hline $\mathrm{p}$ & 0.01 & 0.01 & 0.01 & 0.01 & 0.26 \\
\hline
\end{tabular}

Note: $\mathrm{N}=301$

\subsection{Statistical Significance in Demographic Groups:}

Based on demographic statistics, we found that gender, consumption frequency, monthly income, educational background, types of occupation, work status affect the results, but there is no statistical significance in age and city where participants are based.

Women show higher donation willingness $(\mathrm{t}=-2,27$, $\mathrm{P}<0.05)$ and willingness to follow elephant protection information $(\mathrm{t}=-2.64, \mathrm{P}<0.01)$ than men.

Participants who used to buy elephant-related products show higher consumption willingness $(\mathrm{t}=3.50, \mathrm{P}<0.05)$ and lower protection willingness $(\mathrm{t}=-2.01, \mathrm{P}<0.05)$.

Participants whose monthly income is less than 8000 yuan donate a significantly lower amount of money than those whose monthly average income is 8000 yuan to 19999 yuan $(\Delta \mathrm{M}=-12.04, \mathrm{P}<0.05)$ or those whose monthly average income is more than 20000 yuan $(\Delta M=-19.03$,
$\mathrm{P}<0.01)$.

The consumption willingness of those with master degrees and above is significantly lower than those with associate or bachelor degrees $(\Delta \mathrm{M}=-0.29, \mathrm{P}<0.05)$.

Students' willingness to follow elephant protection information is significantly lower than that of company employees $(\Delta \mathrm{M}=-1.24, \mathrm{P}<0.01)$, staff of government agencies and public institutions $(\Delta \mathrm{M}=-1.20, \mathrm{P}<0.01)$ and the self-employed $(\Delta \mathrm{M}=-1.57, \mathrm{P}<0.01)$.

The protection willingness of full-time employees is significantly higher than that of full-time students $(\Delta \mathrm{M}=0.58, \mathrm{P}<0.05)$ and the retired $(\Delta \mathrm{M}=2.23, \mathrm{P}<0.05)$, while the protection willingness of company owners is significantly higher than that of the retired $(\Delta \mathrm{M}=2.13$, $\mathrm{P}<0.05$ ).

The willingness to follow elephant protection information of full-time employees is significantly higher than that of full-time students $(\Delta \mathrm{M}=-1.08, \mathrm{P}<0.01)$ and the retired $(\Delta \mathrm{M}=2.64, \mathrm{P}<0.05)$, while such willingness of 
company owners is significantly higher than that of fulltime students $(\Delta \mathrm{M}=1.22, \quad \mathrm{P}<0.05)$ and the retired $(\Delta \mathrm{M}=2.78, \mathrm{P}<0.05)$.

\section{Conclusions}

The study found that reading background materials reduces the willingness of participants to consume ivory products, but increases their willingness to participate in elephant protection, their donation willingness and amount. The negative emotion label can reduce more consumption willingness. The female group shows higher donation willingness and willingness to follow elephant protection information. Participants who used to buy elephant-related products show a stronger desire to make another purchase. The high-income group is willing to donate more money, while the group with better educational background shows lower consumption willingness. Staff of government agencies and public institutions, company employees, and business owners have stronger protection willingness. Full-time workers have a stronger interest in following elephant protection information. However, age and city where participants are based do not significantly affect elephant conservation.

\section{Discussions}

This study suggests that positive emotional labels play an important role in pro-environmental behavior while negative emotional labels can enhance environmental selfidentity, which has been proven in previous studies. This paper can guide the design of effective social marketing activities. Traditional campaigns often emphasize how poor the targets perform on a specific topic, which may lead to aversions to requests, or guilt, resistance and resentment [14].

Traditional campaigns also implicitly tell the targets that they are following what others are doing (i.e., they are not making responsible pro-environmental choices), a strategy that has been proven to reinforce undesirable behaviors [15].

When social descriptive norms do not expect targets to engage in what society desires, our alternative plan can serve as an effective supplement to the arsenal of social marketers. This is significant for charitable events and advertisements for public goods in the future. For example, during the fundraising for public goods, negative emotion labels can be leveraged as slogans to raise donations.

Besides, in campaigns such as wildlife protection, publicity should target women organizations such as Women's Federation and fundraising should be oriented towards high-income groups. In the publicity of campaigns for public goods, people aged 31-40 should be the focus.

\section{References}

1. Cook, A. J., Kerr, G. N., \& Moore, K. (2002). Attitudes and intentions towards purchasing GM food. Journal of Economic Psychology, 23(5), 557-572.
2. Conner, M. \& Armitage, C. J. (1998) Extending the theory of planned behavior: a review and avenues for further research, Journal of Applied Social Psychology, 28(15), 1429-1464.

3. Nigbur, D., Lyons, E., \& Uzzell, D. (2010). Attitudes, norms, identity and environ- mental behaviour: Using an expanded theory of planned behaviour to predict participation in a kerbside recycling programme. British Journal of Social Psy-chology, 49, 259-284.

4. Fielding, K. S., McDonald, R., \& Louis, W. R. (2008). Theory of planned behaviour, identity and intentions to engage in environmental activism. Journal of Environmental Psychology, 28,318-326.

5. Whitmarsh, L., \& O'Neill, S. (2010). Green identity, green living? The role of pro-environmental selfidentity in determining consistency across diverse pro-environmental behaviours. Journal of Environmental Psychology,30,305-314. http://dx.doi.org/10.1016/j.jenvp.2010.01.003.

6. Sparks, P., \& Shepherd, R. (1992). Self-identity and the theory of planned behaviour: assessing the role of identification with green consumerism. Social Psychology Quarterly, 55(4), 388-399.

7. Charng, H.-W., Pillavin, J. A., \& Callero, P. L. (1988). Role identity and reasoned action in the prediction of repeated behaviour. Social Psychology Quarterly, 51, 303-317.

8. Gatersleben, B., Murtagh, N., \& Abrahamse, W. (2012). Values, identity and pro-environmental behaviour. Contemporary Social Science, 1-19.

9. http://dx.doi.org/ 10.1080/21582041.2012.682086.

10. Van der Werff, E., Steg, L., \& Keizer, K. (2013). The value of environmental self-identity: The relationship between biospheric values, environmental selfidentity and pro-environmental preferences, intentions and behaviour. Journal of Environmental Psychology, 34,5-563.

11. http://dx.doi.org/10.1016/ j.jenvp.2012.12.006.

12. Van der Werff, E., Steg, L., \& Keizer, K. (2014). I am what I am by looking past the present: The influence of biospheric values and past behaviour on environmental self-identity. Environment and Behavior., 46(5), 626-657.

13. http://dx.doi.org/10.1177/0013916512475209.

14. Link, B. G., Cullen, F. T., Struening, E., Shrout, P. E., \& Dohrenwend, B. P. (1989). A modified labeling theory approach to mental disorders: An empirical assessment. American Sociological Review, 54, 400423.

15. Becker, H. (1963). Outsiders. New York: Free Press. Bonaccio, S., \& Dalal, R. S. (2006). Advice taking and decision-making: An integrative literature review, and implications for the organizational sciences. Organizational Behavior and Human Decision Processes, 101(2), 127-151.

16. Guadagno, R. E., \& Burger, J. M. (2007) Self-concept clarity and responsiveness to false feedback. Social Influence, 2(3), 159-177. 
17. Reich, J. W., \& Robertson, J. L. (1979). Reactance and norm appeal in anti-littering messages. Journal of Applied Social Psychology, 9(1), 91-101.

18. Cialdini, R. B. (2003). Crafting normative messages to protect the environment. Current Directions in Psychological Science, 12(4), 105-109. 